\title{
Burden of Diabetes Type 2 Through Modelling and Simulation
}

\author{
Maja Atanasijević-Kunc ${ }^{1}$ and Jože Drinovec ${ }^{2}$ \\ ${ }^{1}$ University of Ljubljana, Faculty of Electrical Engineering \\ 2 University of Maribor, Faculty for Medicine \\ Slovenia
}

\section{Introduction}

Modelling and simulation represent well established approaches when analyzing systems' properties, their behaviour, predicting possible scenarios, or estimating potential results or responses when influencing the observed system (Cellier, 1991; Cassandras \& Lafortune, 1999; Cellier \& Kofman, 2006; D'Inverno \& Luck, 2010). Such knowledge organization about a given problem can help in its presentation, understanding, explanation and it is also frequently used through system design (Matko et al., 1992).

Modelling and model usage can be classified and/or chosen as methodology regarding different criteria which can in addition be interdependent due to important activities needed in such situations. Criteria can represent the way of data collecting, their form and degree of confidence, model structure and possibilities of model experimentations, the level of problem abstraction and its aggregation, the selection of time granulation, etc. One of the most important aspect (in spite of the fact that it is often not mentioned) which has to be taken into account, is also the goal of modelling which should lead the designer through the whole procedure of model development, its interpretation and experimentation. The last two facts are very important also for the user of developed model. This is perhaps also one of important reasons why very different mathematical approaches and descriptions are used, where the disciplines like medicine, pharmacy and the life sciences are no exception (Hoppensteadt \& Peskin, 2002; Atanasijević-Kunc et al., 2008a; Stahl, 2008; Belič, 2009; Arnold 2010). This is true even in the cases where the same problem, like certain disease development (diabetes for example) is observed.

Here the following questions can arise:

- Which presented or known model regarding certain problem (disease) is the most important or relevant one?

- Should this model be chosen in all situations?

- Can different modelling structures, descriptions or approaches predict the same or very similar results?

- When there is a need to develop a new approach or problem description?

- Is it possible to benefit from the usage of several different descriptions of the same problem?

- If the answer to the previous question is positive, it can be important also to find out, how different descriptions or models can share their results and/or complement each other? 
The answers to the first questions are not surprising. Process descriptions should be suitably chosen regarding modelling goal(s), modelling phase and other important design factors. As indicated in (Stahl, 2008) the investigators should choose the modelling methods that fit the defined problem. It means that different descriptions can predict similar or complementary results using, for example, different complexity (nonlinear or linear descriptions, high or low order descriptions) or different granularity (observation of the whole population, observation of an individual patient, observation of dynamical processes on molecular level), different aggregation (development of one or several diseases) or perhaps only different model presentations are suitable when performing different analysis functions (state space or transfer function description, continuous or discrete time description, time or frequency domain description, ...). Whenever a new point of view of certain problem is under investigation, whenever some new facts or perhaps only different assumptions are taken into account, when modelling results are meant to be used by different groups of people also a new or improved description can be important. All mentioned facts can be verified also when observing different aspects of diabetes mellitus. But, in spite of great diversity of results' description regarding this dangerous chronic disease practically nowhere attention is devoted to the idea of their complementary usage. This viewpoint can become especially interesting when several factors influencing the problem are taken into account.

The literature dealing with different aspects of diabetes has become enormous and very heterogeneous even in the case when searching is limited to mathematical modelling and simulation processes of this disease. Some of them are describing glucose-insulin dynamics (Boutayeb \& Chetouani 2006; Makroglou et al., 2006; Shianga \& Kandeelc 2010), some represent epidemiological descriptions of this non communicable disease (Boutayeb et al., 2004; Boutayeb et al., 2006; Atanasijević-Kunc et al., 2008b), while others describe disease development (Eddy \& Schlessinger, 2003a; 2003b; Kristöfel, et al., 2007) or the relations to risk factors which are in correlation with diabetes development (Brock et al., 2009; MMWR 2004; Atanasijević-Kunc et al., 2008c). Diabetes can represent by itself or even more intense in combination with other possible chronic diseases (dislipidemia, hypertension) or life style (smoking, alcohol consumption, inactivity) the risk for developing different cardiovascular diseases (Levenson et al., 2002; Atanasijević-Kunc et al., 2008c; 2011). Additional aspect, important for modelling structure, can represent social and economical burden of the discussed disease and/or treatment efficacy, which is often interpreted through different pharmacoeconomical studies (Boutayeb et al., 2004; Tarride et al., 2010; Arnold, 2010; Atanasijević-Kunc et al., 2011), where cost-effectiveness analysis and cost - utility analysis provide a basic comparison of different treatment policies or drug efficacy. All mentioned situations can be interpreted as open or closed - loop problems (Atanasijević-Kunc et al., 2008c; 2011; Bellazzi, 2001; Lam, 2002; Makroglou, 2006), where especially in the second case the analysis should take into account stability and sensitivity of system behaviour.

The modelling and simulation approach aims to indicate, use and/or develop mathematical problem presentations which can be used for the evaluation of the burden of diabetes type 2 (D2) mellitus and correlated processes which can contribute to disease development or can represent the source of expenses (direct and/or indirect). This burden is not important only from the economical but also from the social point of view due to the possible severe health complications which usually essentially influence the quality of life.

For the evaluation of mentioned disease burdens regarding certain population it is of most importance first to estimate the number of patients and the treatment expenses. In addition 
also the treatment efficacy can be taken into account which can compare different treatment strategies and/or their influence to further complications development. In addition, of course, also the reasons which influence D2 development can be taken into account, as usually the prevention offers the most effective positive influence to economical and social situation.

This chapter is organized in the following manner. In the next session some modelling structures are indicated which have been used for modelling purposes of D2 presentation. Special attention is devoted to the possibilities of coexistence of different modelling descriptions. Simulation results are illustrated in session 3, where also some of expenses, related to observed patients are estimated. The work ends with conclusion remarks and some ideas for future investigations. It is also important to mention that all presented results were realized using Matlab (Matlab, 2005) with Simulink (Simulink, 2005).

\section{Modelling structures}

One of the simplest presentation which is describing the D2 population, two - compartment linear model, is illustrated in Fig. 1 (Boutayeb et al., 2004). Input signal $\boldsymbol{u}(\boldsymbol{t})$ represents the incidence of D2, while $C(t)$ and $D(t)$ are the numbers of D2 patients with and without complications, respectively. It is expected that patients with D2 are developing complications with $k_{1} D(t)$ rate, in the compartment $C(t)$ they can recover and therefore return to $D(t)$ compartment (with $k_{2} C(t)$ rate), they can die due to natural causes (with $c_{1} C(t)$ rate) or due to severe complications (with $c_{2} C(t)$ rate), and they can also become seriously disabled (with $c_{3} C(t)$ rate). The authors have suggested stability analysis with respect to model parameters and numerical problem solving. In this simple description the population in each compartment is observed as a homogeneous set of patients and it is expected that parameters are time - independent. Important aspects as for example patients' age, life style, body mass, simultaneous joint diseases and similar are not presented explicitly, they can only influence (through the identification process) the values of model parameters. Further extension to nonlinear description was proposed in (Boutayeb et al., 2006), but basic viewpoint remains unchanged.

Far more complex dynamical nonlinear model, as schematically presented in Fig. 2, was originally developed and tuned for the USA (Homer et al., 2004) and later on also adapted with some improvements to the population of Austria (Kristöfel et al., 2007). In comparison to the structure in Fig. 1 this one recognises also the patients with pre-diabetes, not only those where D2 is completely developed, while both groups can be diagnosed or not. So additional four compartments are needed, while special attention was devoted also to the transition flows, which are dependent on a great number of important factors and ratios, like population age, obesity, activity and similar. One difference in comparison to model in Fig. 1 is also the interpretation regarding patients with complications, as they can't reach the state without complications anymore.

It is important to mention that authors have in this last case devoted detailed attention to the validation and verification of proposed models using extensive data, which are in general not available for all countries. Due to model complexity sensitivity and stability analysis demanded the introduction of expected range of variables' changes and simulation testing. When economical burden of disease treatment and/or treatment efficacy is of interest in many cases the so called decision modelling techniques are used (Arnold, 2010). Decision trees have been for more than forty years the most common and simplest formalism, 
comprising choices, chances, and outcomes. For the similar situation as in previous two presentations the idea is indicated in Fig. 3.

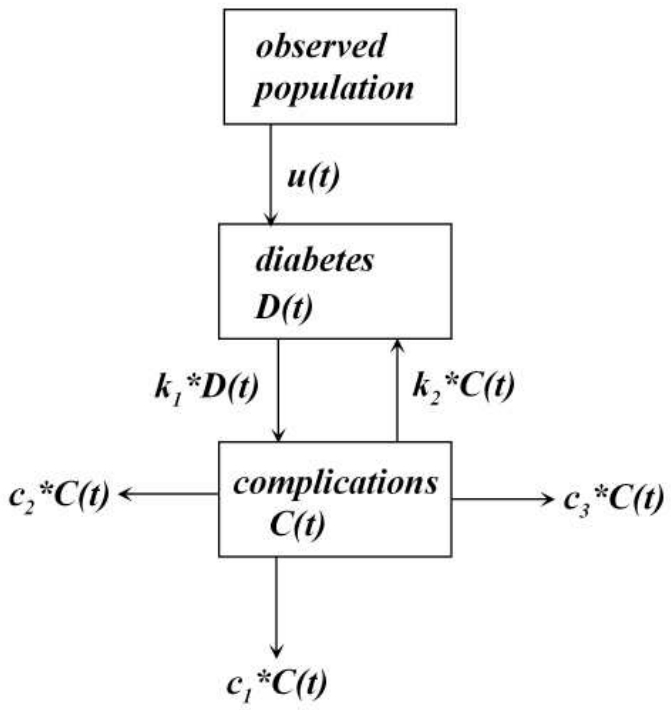

Fig. 1. Two - compartment modelling structure

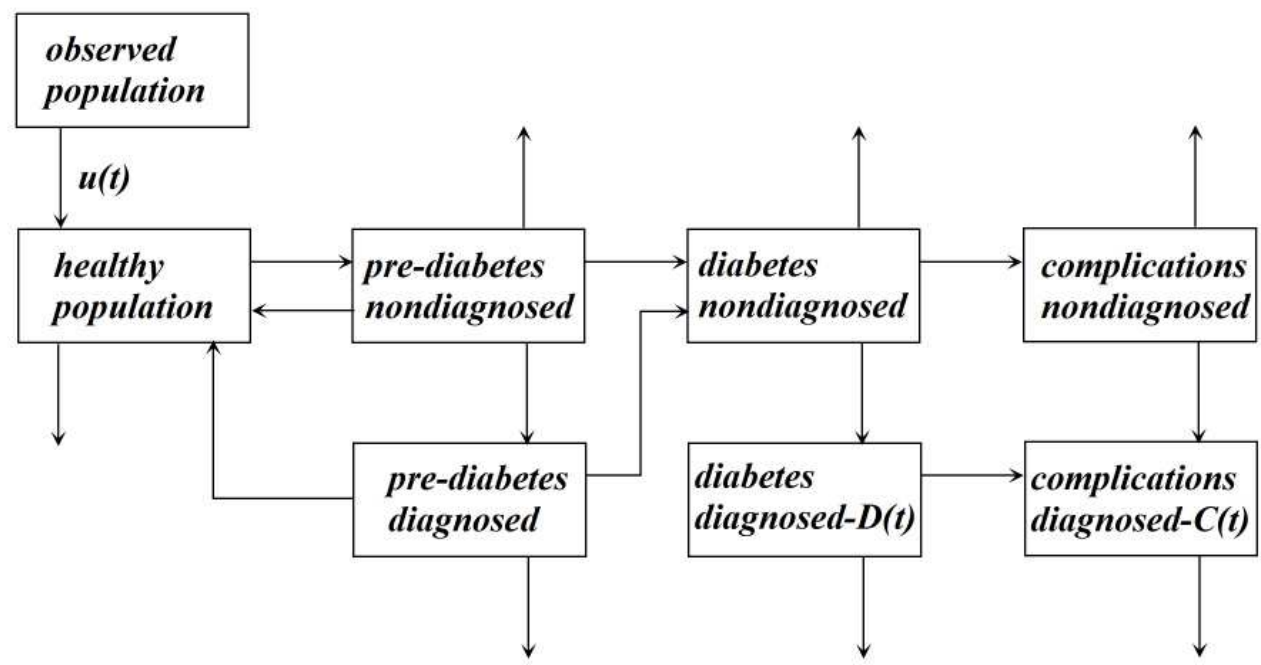

Fig. 2. System dynamics model for the diabetes prevalence 


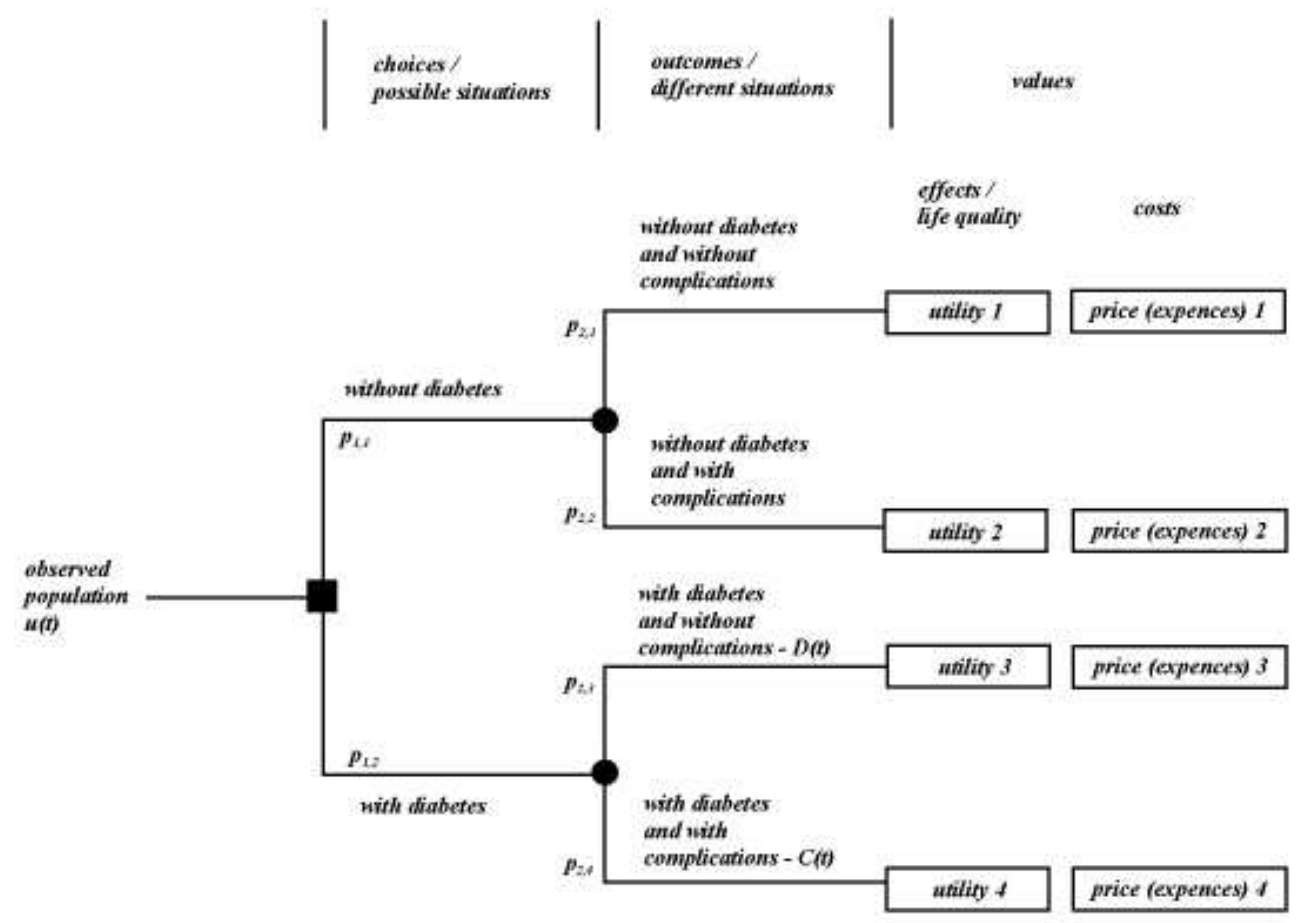

Fig. 3. Decision tree modelling structure

Such problem presentations are static and they don't enable the observation of patients' history, as in the previously mentioned cases. In problems that lead to long - term differences in outcome such presentation can be insufficient. One way to avoid (at least partly) this drawback is to use the description in the form of the so called Markov process (Stahl, 2008; Shih, 2007) or to extend the decision tree to include also Markov processes, for example at the outcome node as illustrated in Fig. 4 (Arnold, 2010). The advantages of such presentations are that they are relatively simple, frequently used and therefore also well accepted as abstract problem presentation. But there are also two main limitations (Stahl, 2008; Arnold, 2010). State transitions can only occur at the end of a cycle, which can create some biases, and Markov cycle time may force the analyst to make simplifying assumptions regarding transition probabilities.

Economical burden regarding the situation inside the observed population was investigated also by (Briggs \& Sculpher, 1998; Atanasijević-Kunc et al., 2008b; 2008c; 2011). When summarizing the mentioned results the modelling structure can be presented as illustrated in Fig. 5. The problem presentation and design is separated into three main phases. Through the first phase risk factors and chronic diseases are described in the form of prevalence distribution regarding patients' age, in the second design phase also the prevalence of different complications are added, where among the patients with more problems indicated in the first phase or in the case where chronic diseases were not correspondingly treated, also the development of complications was more frequent. Input signal to the first phase is 
unity step indicating the start of problem observation, namely at the birth. The results from the first and the second phase are entering the third phase together with input signals $\boldsymbol{u}_{2}(\boldsymbol{t})$ and $u_{3}(t)$. Input signal $u_{2}(t)$ provides the information regarding the number of people in the observed population with respect to their age, while with $\boldsymbol{u}_{3}(t)$ also the prices for needed treatment are defined. Combining the signal $\boldsymbol{u}_{2}(t)$ with calculated prevalence distribution enables the definition of patients' number in the observed population, and using the prices from $\boldsymbol{u}_{3}(\boldsymbol{t})$ also the economical burden can be calculated.

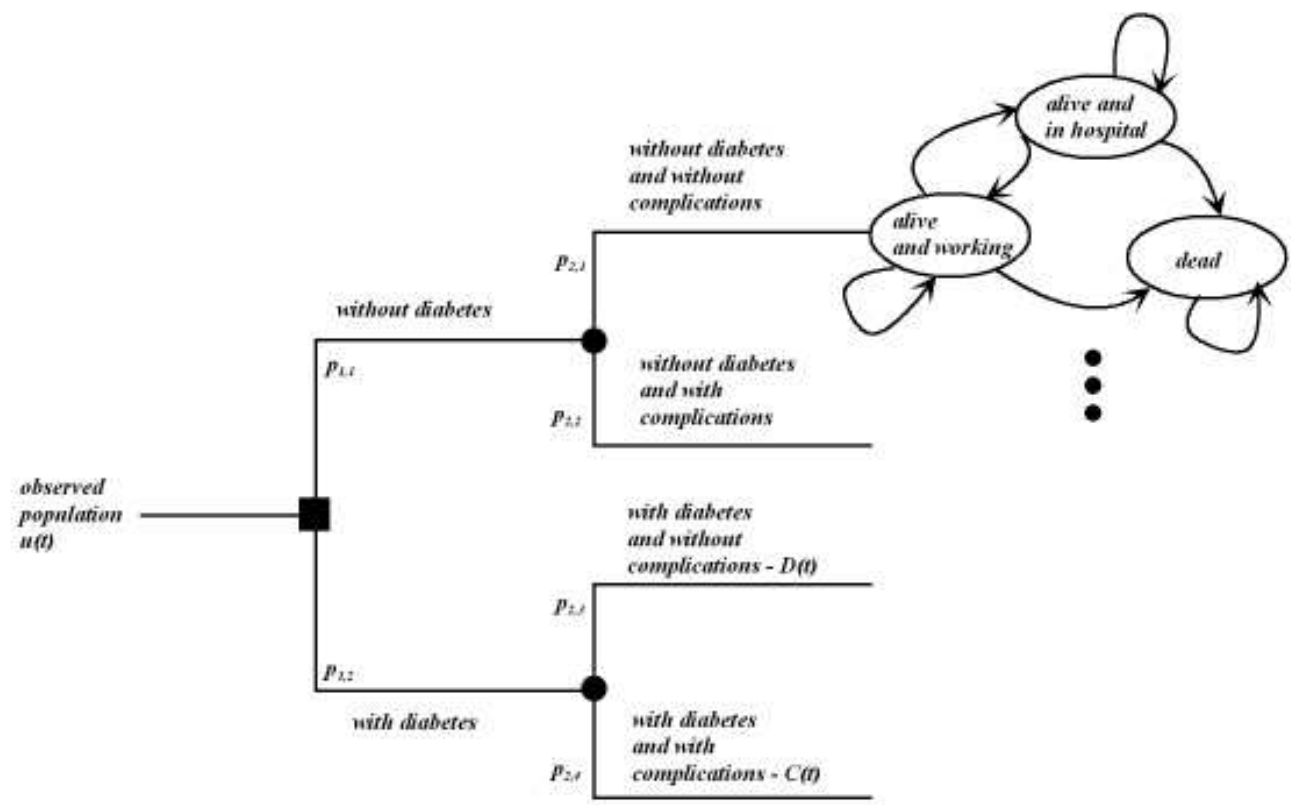

Fig. 4. Usage of Markov processes in decision tree structure

Presented structure gives very good insight how patients are distributed regarding their age and also how this influences the economical burden of observed population. In the case of similar disease distribution only demographic data can be changed and perhaps (if essentially different also) prices and model gives the estimation of patients' number or treatment economical burden for another country or group of people. This approach is therefore especially interesting for the countries or areas for which national diseases registers are not available. But, the drawback of this mathematical presentation is, that it is very difficult to identify the influence on population, which is the result of some actions realized on only one part of the population where also the transient response due to dynamical system properties should be taken into account. To indicate how to overcome this problem let's present only one part of the situation from Fig. 5 and from a slightly different view point. The idea is illustrated in Fig. 6 taking into account also the possibility of coexistence of different dynamical processes descriptions. 


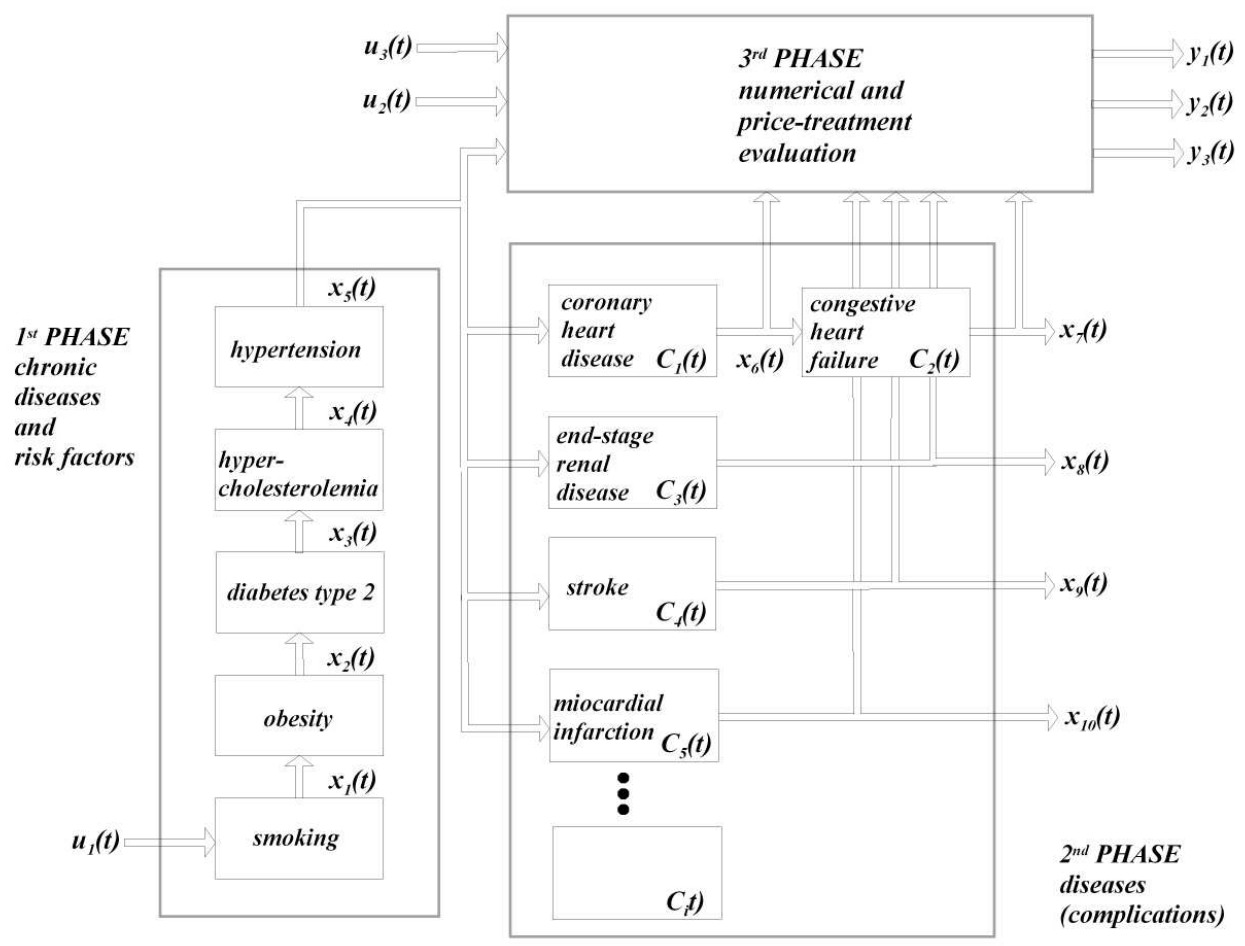

Fig. 5. Diseases prevalence, number of patients and expenses presentation

Here D2 is a disease of the third level due to the fact that on one side risky and/or unhealthy life style (population status observed in the second level of the structure) can influence the development of this chronic disease, but D2, as already mentioned, can also contribute to development of different health complications (presented at the fourth level of the proposed structure). At the second level two important problems, namely activity or inactivity and obesity are taken into account, which are two most important problems leading to D2 (Defay et al., 2001; DPPRSG, 2002; Kriska et al., 2003; Mokdad et al., 2003; ADA, 2007;).

D2 is usually preceded by a pre-diabetes (" a metabolic condition characterised by insulin resistance and primary or secondary beta cell dysfunction which increases the risk of developing type 2 diabetes and cardiovascular disease" (Tuomilehto et al., 2001; Valensi et al., 2005). It is extremely common, especially in elder population (40+). Efficient pharmacological therapies are known, which can be very efficient together with lifestyle interventions in prevention or delayed D2 development.

As mentioned processes are observed regarding certain population, an important influence to overall situation can contribute also demographic changes which are influencing the system's states at the first level.

Expenses are here presented as a static property, but can be in the future extensions reformulated to indicate the results of economical and financial flows. 


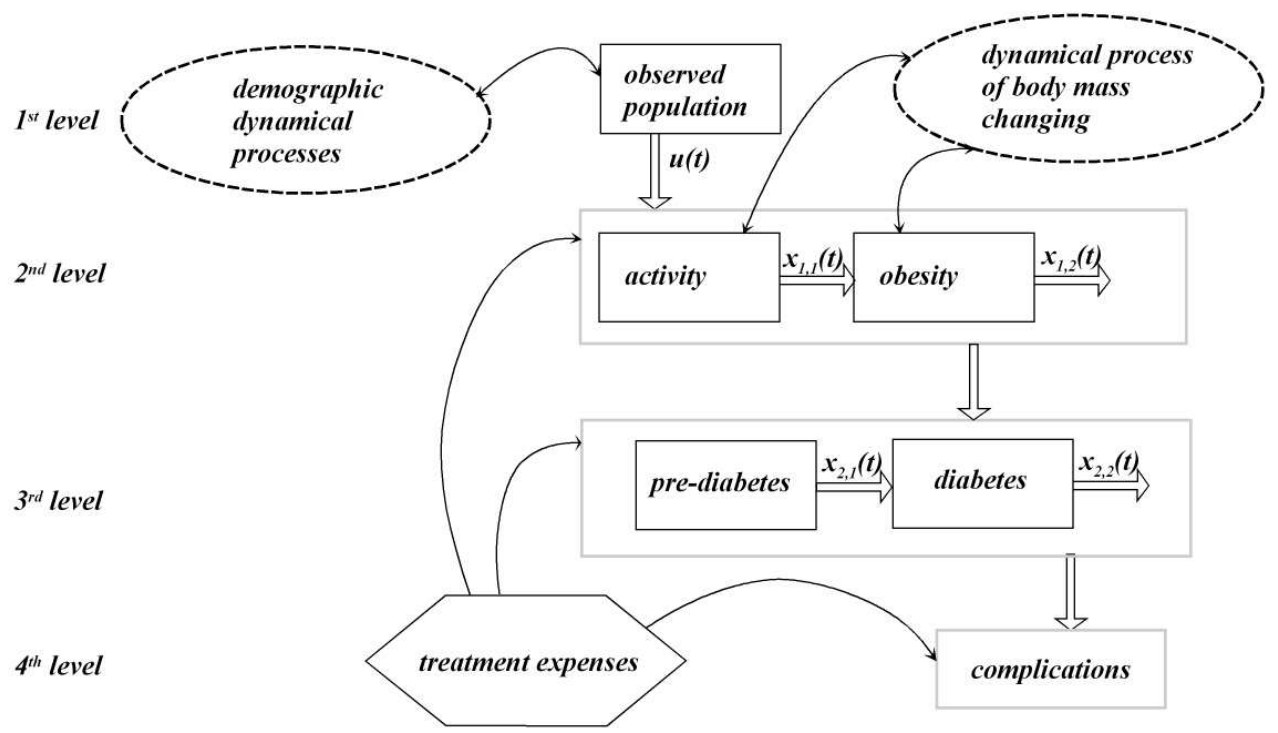

Fig. 6. Limited sub-problem with dynamic processes at different levels

\section{Simulation results}

Modelling procedure of the structure indicated in Fig. 6 has started by observing the available information regarding the prevalence of population activity/inactivity and obesity as they are closely related to the probability of developing D2. It is important to mention that statistical data differ slightly for different world areas (Berghöfer et al., 2008; WHO, 2011a), but data for larger countries seem to be reliable also for the countries with comparable demographic, economic and social situation.

As very well known, activity has a significant direct influence to body weight and especially to adequate body mass maintainance, but is important also by itself as a prevention regarding the development of D2 (Defay, 2001; Brock, 2009). In adult population to the group of high active are classified those, who are active 30 minutes or more on at least five days a week, medium active are those, who are active 30 minutes or more 1 to 4 days a week, other are low active. In children the following division was adopted: high (recommended): 60 minutes or more on all 7 days per week; medium: 30-59 minutes on all 7 days per week; low: lower level of activity. Usually activity in men and women slightly differ (men and boys are slightly more active), but average data, which were used for modelling purposes, are summarized in Table 1 (British Heart Foundation Statistics Website, 2008).

Overweight and obesity are defined as abnormal or excessive fat accumulation that may impair health. The number of these people is constantly increasing and consequently the World Health Organization (WHO, 2000) has recognized obesity being a disease too and as such it deserves far more attention. It is mainly a consequence of unbalance between energy intake and energy expenditure in each individual.

For adults, overweight and obesity ranges are determined by using weight and height to calculate a number called "body mass index" (BMI). It is defined as the weight in kilograms 
divided by the square of the height in meters $\left(\mathrm{kg} / \mathrm{m}^{2}\right)$. BMI is used because, for most people, it correlates with their amount of body fat. However, it should be considered as a rough guide because it may not correspond to the same degree of fatness in different individuals.

WHO defines "overweight" as a BMI equal to or more than 25, and "obesity" as a BMI equal to or more than 30 (WHO, 2011b). WHO's latest projections indicate that globally in 2005 approximately 1.6 billion adults (age 15+) were overweight and at least 400 million adults were obese. Children were defined as overweight or obese using the $85^{\text {th }}$ and $95^{\text {th }}$ percentiles of the reference curves. At least 20 million children under the age of 5 years were overweight globally in 2005. Once considered a problem only in high-income countries, overweight and obesity are now dramatically rising in low- and middle-income countries, particularly in urban settings. The prevalence of obesity differs from country to country and is also different regarding men and women. An average situation, which can be taken into account for most European countries, is presented in Table 2 (British Heart Foundation Statistics Website, 2010).

From data given in Tables 1 and 2 it is clear that activity or inactivity, as well as overweight and obesity can, regarding the whole observed population, be interpreted as dynamical processes where age of people is represented as independent variable.

In Fig. 7 the model response is illustrated which shows that activity is decreasing through the whole life time and is becoming especially intensive after the age of 40 . When activity is defined also the prevalence of inactive are known, as is indicated in Fig. 8. The dynamical structure which gives the responses presented in Figs. 7 and 8 was identified so that good matching was achieved with data in Table 1 (dynamical nonlinear model of $11^{\text {th }}$ order).

\begin{tabular}{|c|c|c|c|c|c|c|c|c|}
\hline $\begin{array}{c}\text { age } \\
\text { [years] }\end{array}$ & 0 & 1 & 2 & 3 & 4 & 5 & 6 & 7 \\
\hline $\begin{array}{c}\text { average } \\
{[\%]}\end{array}$ & 70 & 69 & 68.5 & 69 & 70 & 62 & 62.5 & 69 \\
\hline $\begin{array}{c}\text { age } \\
\text { [years] }\end{array}$ & 8 & 9 & 10 & 11 & 12 & 13 & 14 & 15 \\
\hline $\begin{array}{c}\text { average } \\
{[\%]}\end{array}$ & 68.5 & 64.5 & 64.5 & 64 & 64.5 & 64.5 & 58.5 & 56.5 \\
\hline $\begin{array}{c}\text { age } \\
\text { [years] }\end{array}$ & $16-24$ & $25-34$ & $35-44$ & $45-54$ & $55-64$ & $65-74$ & $75+$ & \\
\hline $\begin{array}{c}\text { average } \\
{[\%]}\end{array}$ & 43 & 44 & 40.5 & 36 & 31 & 18.5 & 6.5 & \\
\hline
\end{tabular}

Table 1. Prevalence of high active population

\begin{tabular}{|c|c|c|c|c|c|}
\hline age [years] & $2-15$ & $16-34$ & $35-54$ & $55-74$ & $75+$ \\
\hline $\begin{array}{c}\text { average prevalence: } \\
25=<\text { BMI<30 [\%] }\end{array}$ & 13.5 & 27 & 39 & 41.5 & 37.5 \\
\hline $\begin{array}{c}\text { average prevalence: } \\
\text { BMI=>30 [\%] }\end{array}$ & 16 & 19 & 33.5 & 31.5 & 22.5 \\
\hline $\begin{array}{c}\text { average prevalence: } \\
\text { BMI=>25 [\%] }\end{array}$ & 29.5 & 46 & 72.5 & 73 & 60 \\
\hline
\end{tabular}

Table 2. Prevalence of overweight $(25=<\mathrm{BMI}<30)$ and obese population $(\mathrm{BMI}=>30)$ 
It is important to note that such representation enables the extension of decision tree formalism to comprise also a time component, namely the age of observed people (and/or patients). This time component is of crucial importance also regarding the prevalence of great number of chronic diseases and corresponding consequences. Another advantage is that when certain population is observed these responses can be combined with demographic data to evaluate the number of observed people.

In Fig. 9 the result of the last count of the population in Slovenia in 2003 is illustrated. When combined with the prevalence of activity in Fig. 7 it becomes clear that in Slovenia around 780000 people or $39 \%$ are active, while other $61 \%$ do not match this criteria. Distribution of the number of active people regarding their age is presented in Fig. 10.

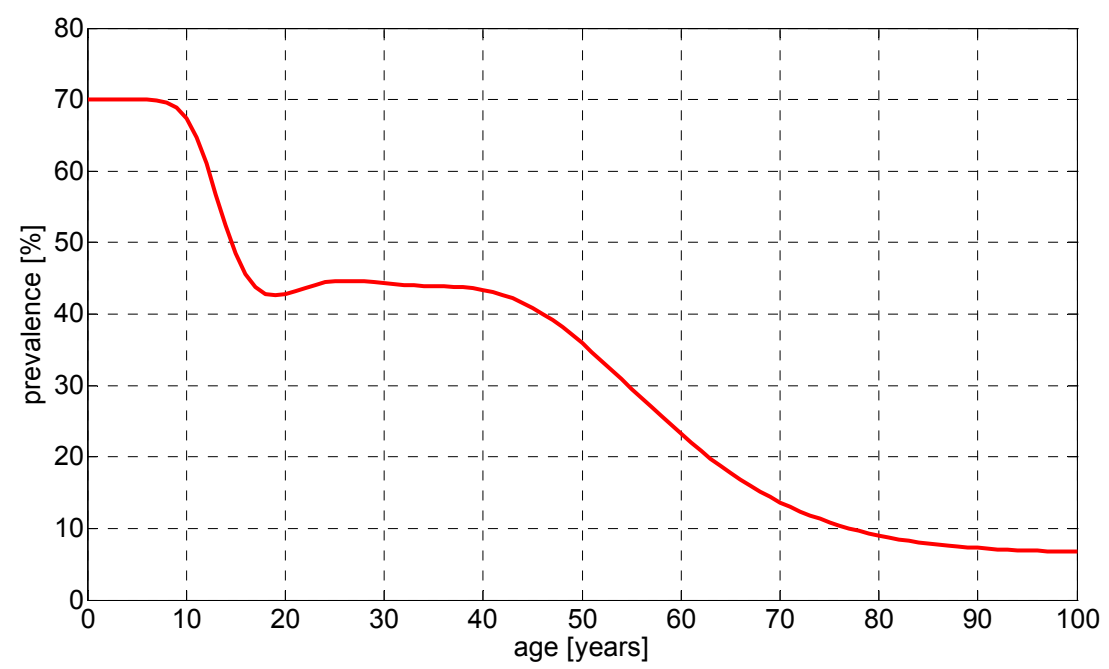

Fig. 7. Prevalence of activity

Two output signals from the block "activity" (see Fig. 6) are entering the block "obesity". For modelling purposes the information from Table 2 was used. It is clear that the ratio between overweight and obese population is slightly changing through the life time, but as these changes are not very distinctive the assumption that it is equal to 1.33 (average value from Table 2) is taken into account.

It is also very well known that active life style has very good influence also to body mass and in contrary people who are obese are inclined to inactivity, but there is practically no quantitative data available regarding the statistical correlation on the population level among these two variables. The interesting exception represents the paper of Brock (Brock et al, 2009), where the association between insufficiently physically active and the prevalence of obesity is described for the USA in the form of linear regression model. Testing this description in comparison to information from Table 2 and presented activity response showed that it is expected the prevalence of obesity to be slightly lower in EU countries. Further nonlinearity can be presumed which can mainly be the reason of the fact that activity is essentially decreasing especially after the age of 45 (see Fig. 7). 


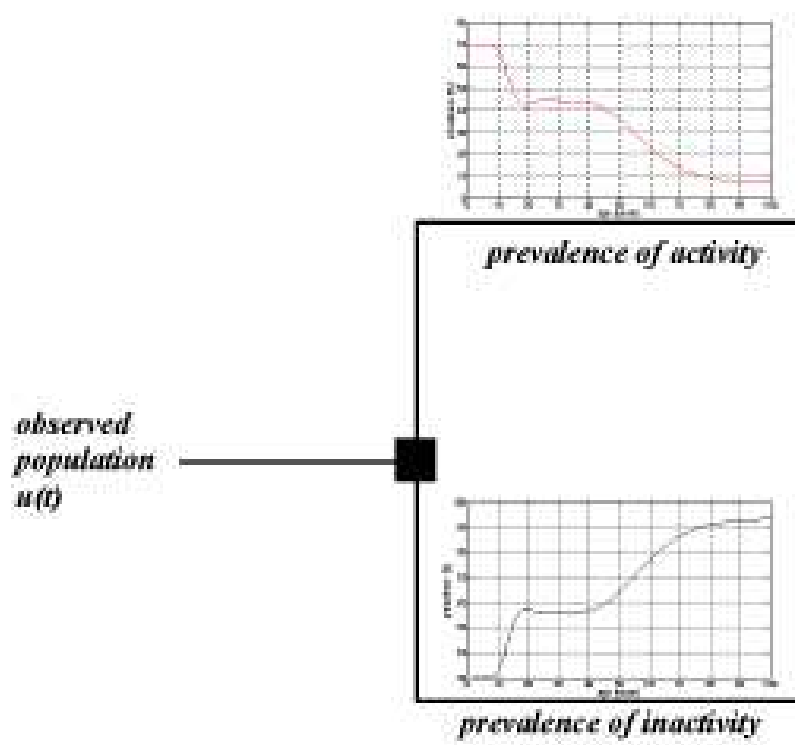

Fig. 8. Prevalence of activity and inactivity in observed population illustrated through decision tree

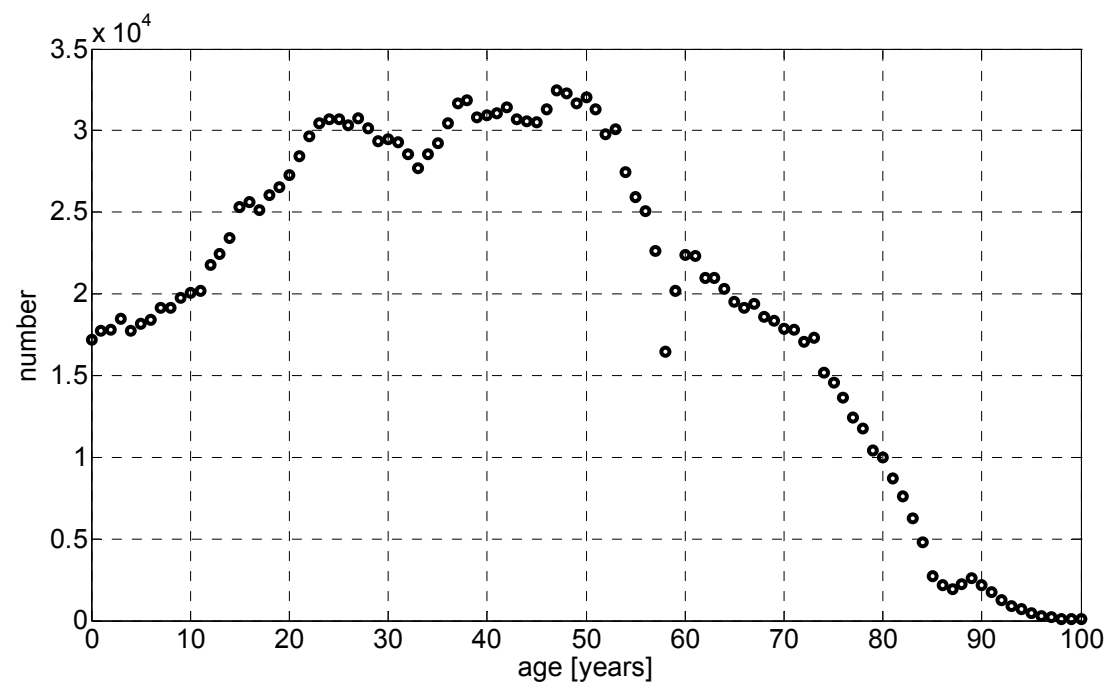

Fig. 9. Number of people in Slovenia 


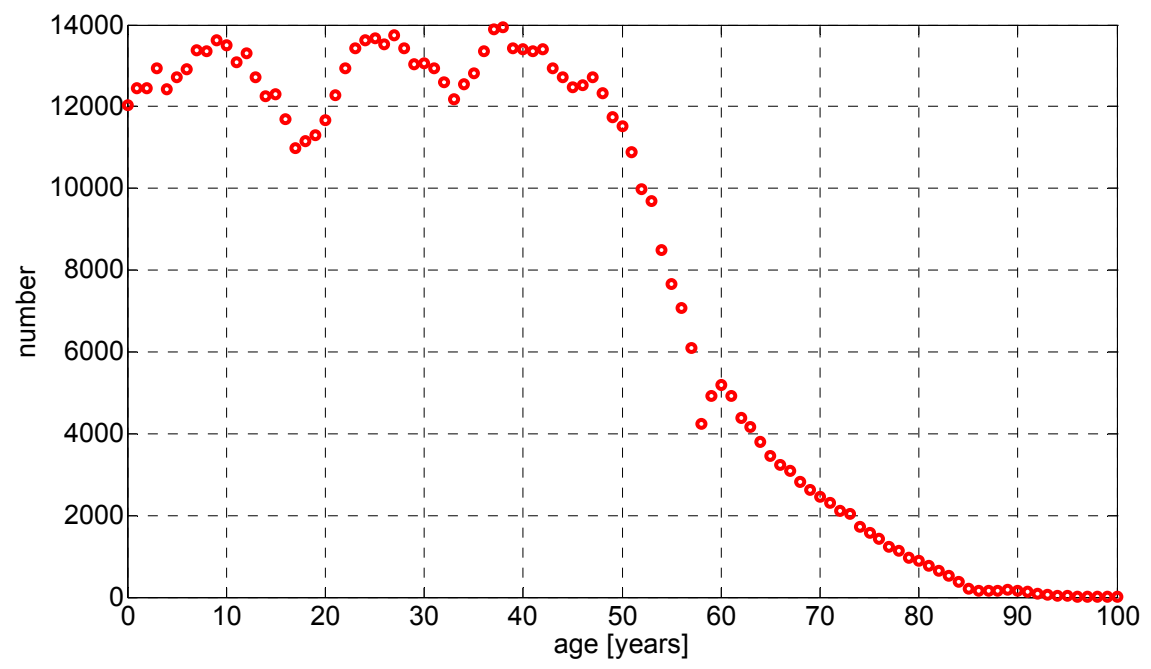

Fig. 10. Number of active people in Slovenia

Taking into account all mentioned data the mathematical model (11 ${ }^{\text {th }}$ order with time delays) of overweight and obese population was identified and responses are presented in Fig. 11. It is also possible to differ among overweight and obese taking into account mentioned ratio.

When prevalence functions are defined also the number of these people can be calculated (Fig. 12). Regarding the presented model in Slovenia live over 1 million people who have BMI equal to or greater than 25 or with other words almost $55 \%$ of population have higher body mass as recommended. Among these people around 300000 are active while others are not.

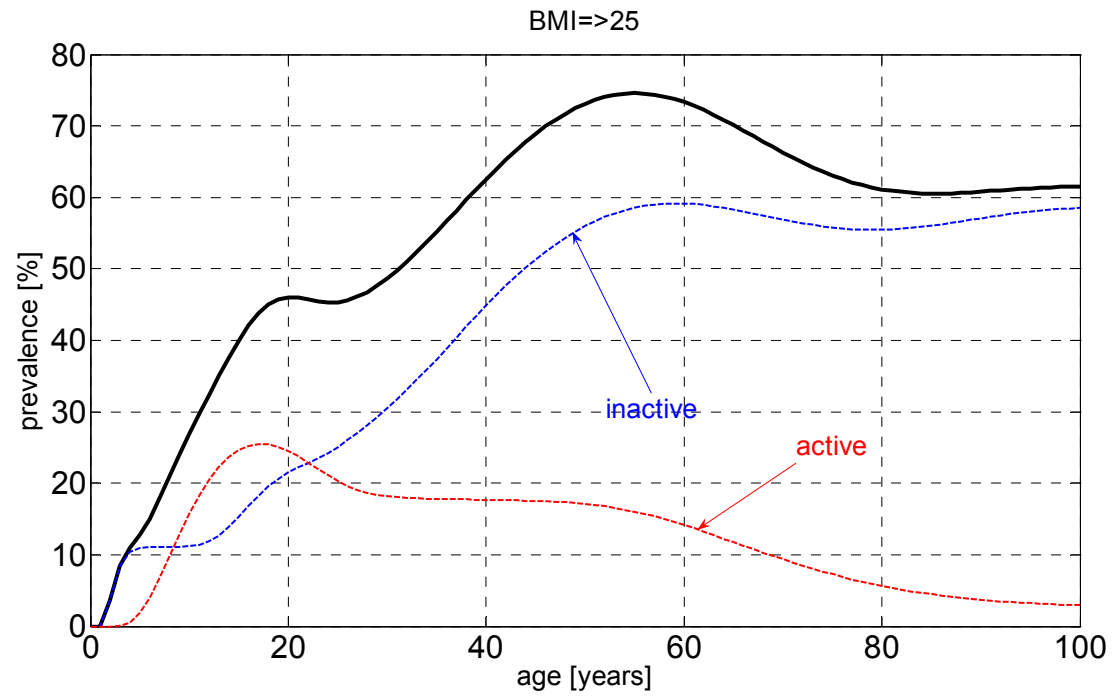

Fig. 11. Prevalence of population with $B M I=>25$ 
Both, inactivity and obesity are very important regarding the development of D2 (Valensi et al., 2005). It was discovered that most adults (85.4 - $86 \%$ in average) with diagnosed diabetes were overweight or obese (MMWR, 2004), 52\% were obese, and $8.1 \%$ had morbid obesity (Daousi, 2006). Before this chronic disease is fully developed patients have a pre-diabetes which in general significantly differ from D2 regarding the fact that when strict life change is adopted taking into account corresponding diet and activity, sometimes complemented by drug treatment, patients can return to normal state. Sometimes this transition is (for example due to long lasting pre-diabetes) not possible, but in such situations D2 development is in most cases significantly postponed. Pre-diabetes is not a true disease but can be interpreted as a serious risk factor for developing D2 and cardiovascular diseases. Over $30 \%$ of people with pre-diabetes develop D2 within 5 years (Valensi, 2005). The average conversion rate was estimated at $5.8 \%$ per year with wide variations which depend on differences in age, BMI, ethnicity, etc.. It is very important to accent that several welldesigned randomized controlled trials (Valensi, 2005) have been reported that categorically confirm the benefits of interventions in pre-diabetes. Standardized diet with reduced food intake, increased physical activity and sometimes also additional drug treatment can reduce the incidence of D2 for almost $60 \%$ (in mentioned studies from $25 \%$ to $58 \%$ ). But, it is important to point out that intensive lifestyle modification was nearly twice as effective in preventing D2. It is therefore evident that active management of pre-diabetes can be very effective in preventing the progression of diabetes.

For modelling purposes the information given in Tables 3 (Narayanappa et al., 2011; Li, et al., 2009; NDS, 2011; Valensi et al., 2005) and 4 (Behl et al., 2004) was taken into account. Again the average data between men and women are presented.

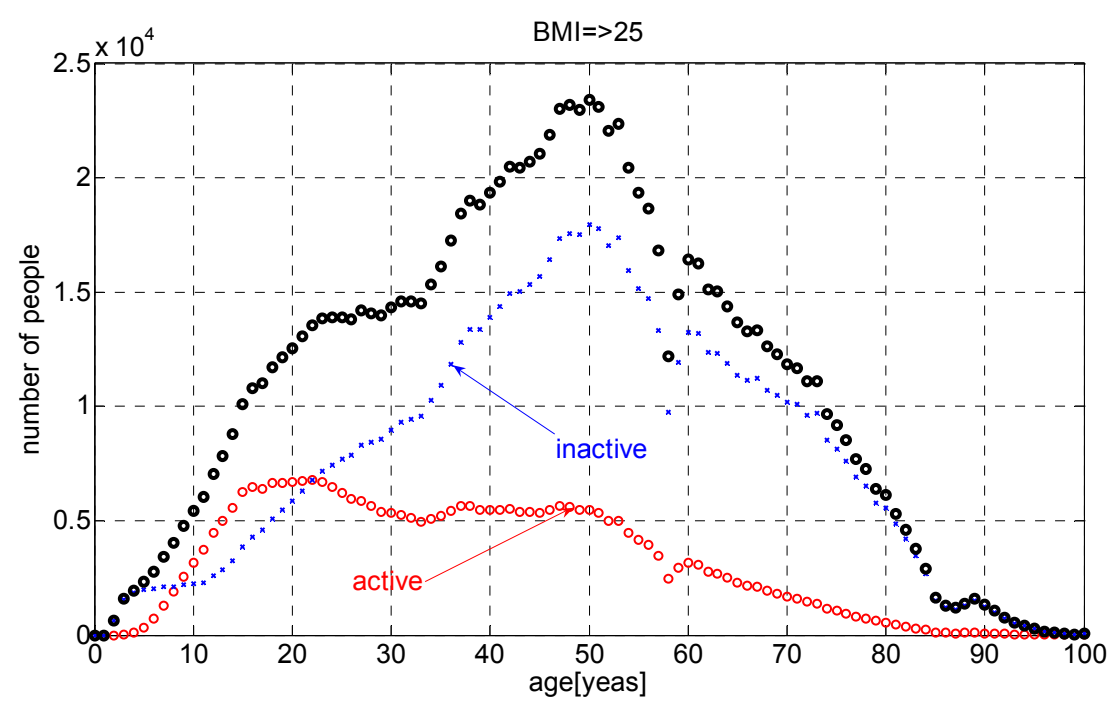

Fig. 12. Number of people in Slovenia with $B M I=>25$ (active and inactive) 


\begin{tabular}{|c|c|c|c|c|c|}
\hline $\begin{array}{c}\text { age } \\
\text { [years] }\end{array}$ & $5-11$ & $12-19$ & $20+$ & $40-75$ & $65+$ \\
\hline $\begin{array}{c}\text { average } \\
\text { prevalence } \\
{[\%]}\end{array}$ & 3.7 & 16.1 & 35 & 40 & 50 \\
\hline
\end{tabular}

Table 3. Prevalence of pre-diabetes

\begin{tabular}{|c|c|c|c|c|c|}
\hline $\begin{array}{c}\text { age } \\
\text { [years] }\end{array}$ & $25-34$ & $35-44$ & $45-54$ & $55-64$ & $65+$ \\
\hline $\begin{array}{c}\text { average } \\
\text { prevalence } \\
{[\%]}\end{array}$ & 3.5 & 4.2 & 8.9 & 15.5 & 19 \\
\hline
\end{tabular}

Table 4. Prevalence of diabetes type 2

In Fig. 13 model responses are given regarding pre-diabetes $\left(16^{\text {th }}\right.$ order model with time delays) and D2 (5th order with time delays), what further enable the calculation of observed patients with respect to their age, what shows Fig. 14. It can be concluded that in Slovenia live around 611000 patients with pre-diabetes, or with other words, approximately $30 \%$ of the population is in such state. In addition almost 144000 are D2-patients, or over $7 \%$ have developed this serious chronic disease. Among this group of patients $85.7 \%$ are overweight or even obese.

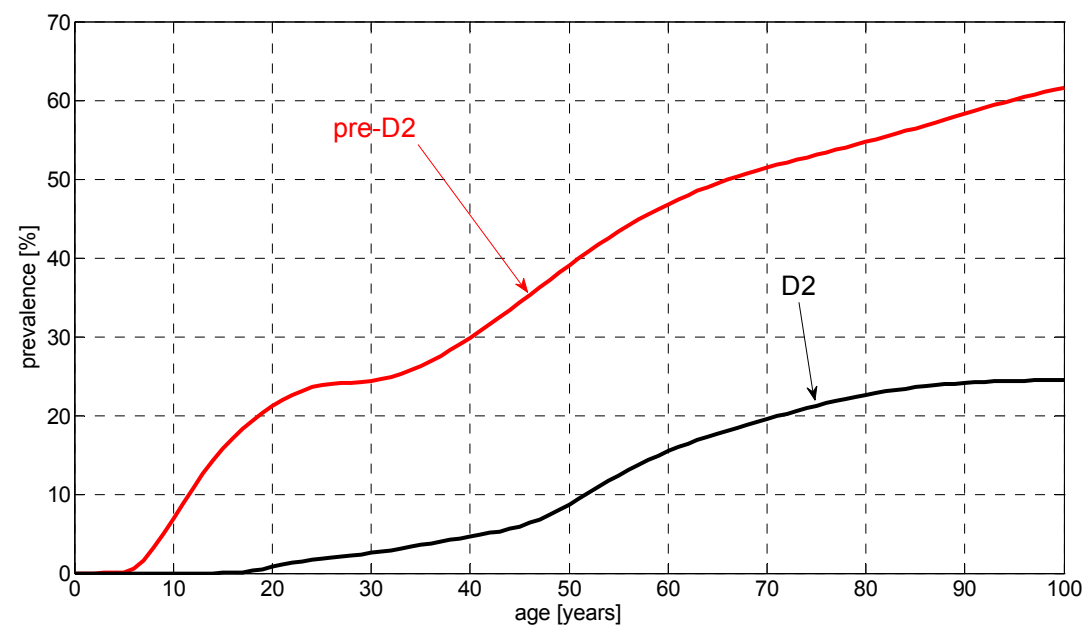

Fig. 13. Prevalence of pre-diabetes and D2 


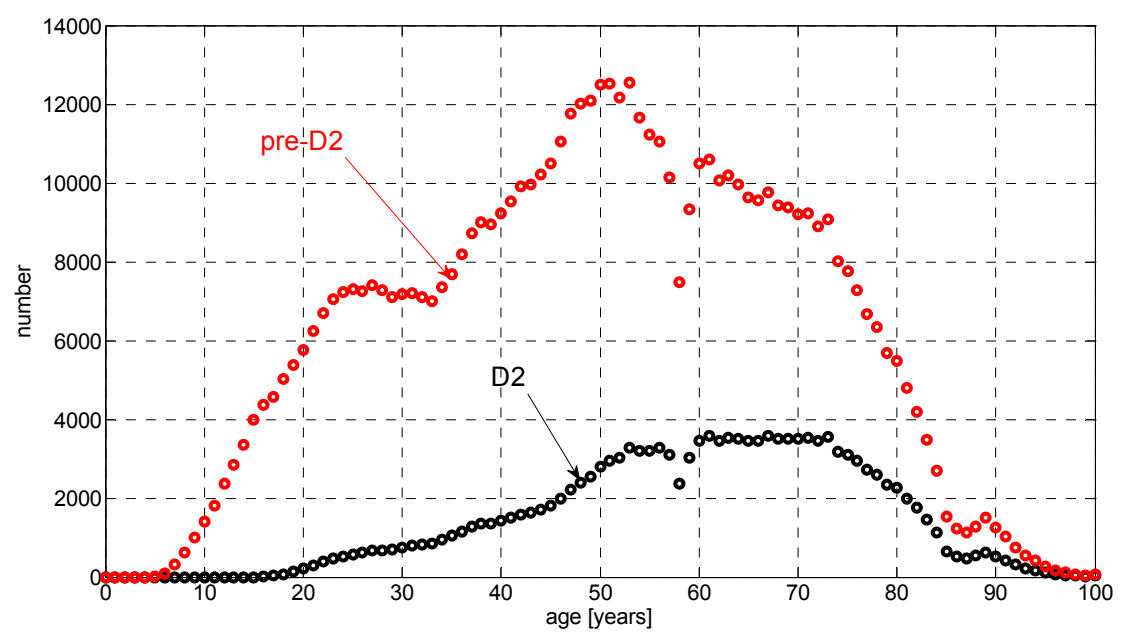

Fig. 14. Number of patients with pre-diabetes and D2 in Slovenia

In this design phase also some of expenses needed for observed patients can be indicated. For the population with higher mass it is possible to find out that a great majority of these people would like to loose their overweight. Some of them are experimenting with different diets, around $20 \%$ of adult population (from 18 to 60 ) also use drugs, and around $5 \%$ from the age window of 40 to 60 use the help of medical experts. In some special cases also surgical help is needed. In Slovenia in average around 100 such surgical operations per year can be expected. More and more frequent are also cosmetic surgical operations, but were not taken into account here as they are mainly performed in private institutions and data are not available.

It was estimated, that for one overweight or obese patient the year price for drugs is $€ 447.96$, what represents an economic burden of $€ 66.88$ million per year (for $20 \%$ of adult population between 18 to 60). As year treatment by medical expert represents economical burden of around $€ 3000$ for this group additional $€ 63.4$ million is used (for $5 \%$ from the age window of 40 to 60). Prices for surgical operations differ drastically. In Slovenia for such intervention $€ 7200$ is needed for one patient or $€ 720000$ per year for the whole country. All together this represents $€ 131$ million per year of direct costs or in average around $€ 130$ each year for each from the group of obese or overweight persons.

An average year treatment price for one D2 patient was estimated to be $€ 355$ (AtanasijevićKunc et al., 2008c) (general practitioner: 4 times / year, laboratory: 2 times / year, drugs), representing economical burden of over $€ 51$ million per year. It is important to observe that the maximum number of these patients can be expected inside the age window of 55 to 75 . As population in Slovenia, similar to other EU countries, is getting older, in the future decades this burden can become even more serious.

To estimate such population changes mathematical model was developed taking into account average statistical parameters using data (fertility, mortality and migrations) from 2004 to 2007 as presented by Statistical Office of the Republic of Slovenia (SORS, 2011). Fertility was calculated regarding the number of people in the age window from 18 to 45 . It 
was estimated that each year $2.2715 \%$ newborns are expected regarding the mentioned group of people. The realized prediction starts in 2003 and illustrates the expectations till the year 2052. The situation is illustrated in Fig. 15. An important observation from this figure is that the number of people after the age of 60 is expected to increase while the younger population, including also the majority of working people, is diminished. Combination of modelling results from Fig. 15 and the prevalence of D2 model is shown in Fig. 16.

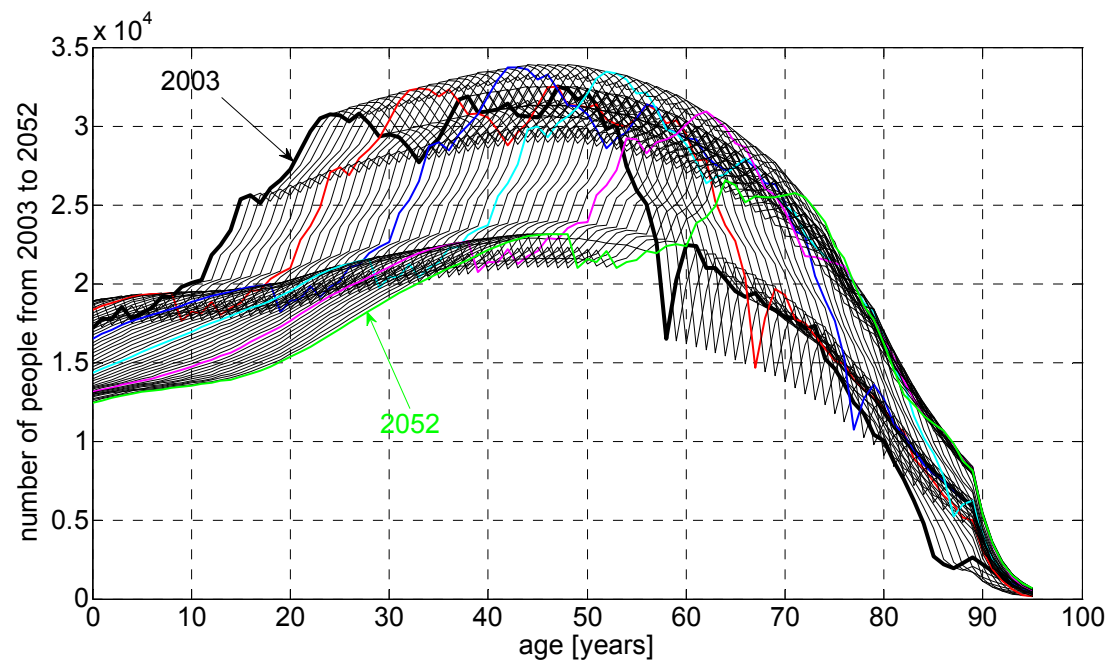

Fig. 15. Number of people in Slovenia from 2003 to 2052

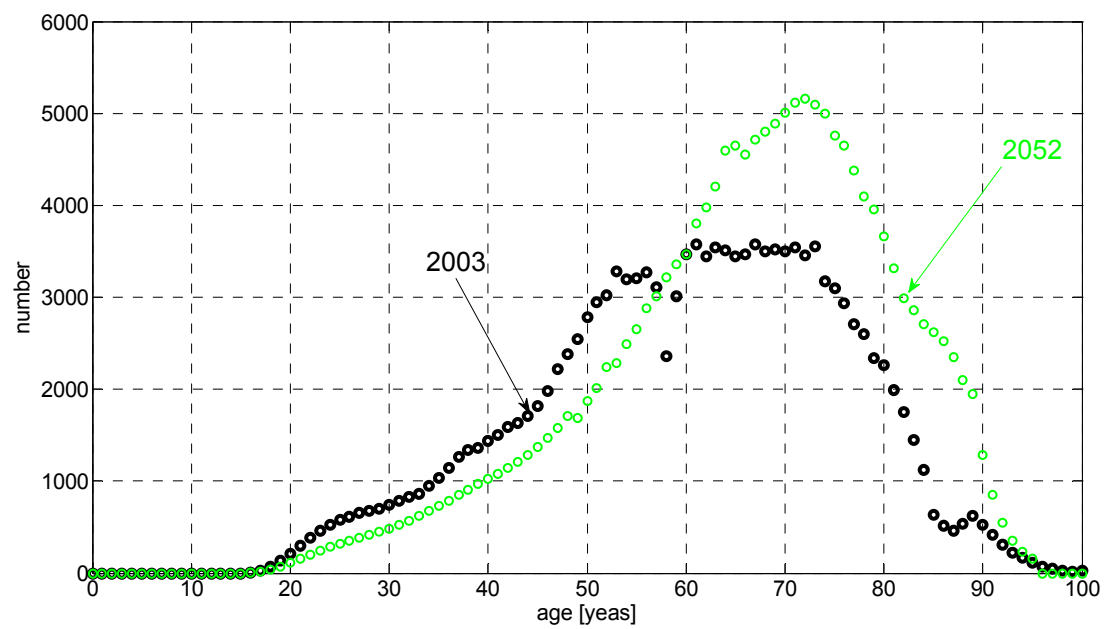

Fig. 16. Number of D2 patients from 2003 to 2052 
The number of D2 patients in younger population is expected to decrease as the number of younger population is also decreasing, but after the age of 60 the number of D2 patients is essentially higher. The ratio between the number of D2 patients and the number of active people (people between 20 and 60) in 2003 equals 0.1208 , while in 2052 it is expected to rise to 0.2036 . This means that for active population only regarding D2 patients the economic burden is expected to increase for $68.5 \%$ if the prevalence of this disease remains unchanged.

Here it is important to point out also the following additional facts:

- As revealed in (NDS, 2011) the average medical expenditures for the people with diagnosed D2 are 2.3 times higher than that for the people without D2.

- The prevalence of several other chronic diseases and different complications are higher among older population (Atanasijević-Kunc et al., 2008a, 2008b, 2008c).

Therefore it would be of great importance to indicate and evaluate some solutions which would decrease this enormous social and economical burden.

The increase of activity is, regarding medical recommendation, the first step which can represent an improvement in desired direction, and the second is of course body mass reduction. To estimate the interdependence of mentioned variables in a quantitative manner two-compartment mathematical model was used (Chow \& Hall, 2008), enabling to differ among fat-free body mass $(f f m)$ and fat mass $(f m)$. Equation for daily energy balance is:

$$
e b(t)=e i(t)-e e(t)
$$

where $e i(t)$ represents daily energy intake and $e e(t)$ daily energy expenditure in $k c a l$. Energy intake depends on food and its caloric value:

$$
e i(t)=k_{1} c i(t)+k_{2} f i(t)+k_{3} p i(t)
$$

$c i(t)$ indicating carbohydrate intake, $f i(t)$ fat intake and $p i(t)$ protein intake while constants $k_{i}$ are: $k_{1}=4 \mathrm{kcal} / \mathrm{gram}, k_{2}=9 \mathrm{kcal} / \mathrm{gram}, k_{3}=4 \mathrm{kcal} / \mathrm{gram}$. It is recommended that protein intake represents $20-30 \%$, fat intake $15-20 \%$ and carbohydrate intake $55-60 \%$ of daily food intake. Daily energy expenditure is calculated as follows:

$$
e e(t)=t e f(t)+p a(t)+r m r(t)
$$

where tef(t) is thermic effect of feeding which usually ranges from 7 to $15 \%$ of the total energy intake (11\% in our case), $p a(t)$ represents energy spent on physical activity and $r m r(t)$ is the so called resting metabolic rate. It refers to the energy needed to maintain basic physiological processes. It represents a substantial percentage (45-70\%) of energy expenditure for the typical individual (HER, 2001). It mainly depends on $f f m(t)$ and was approximated with:

$$
r m r(t)=500+22 f f m(t)
$$

The daily energy balance $e b(t)$ is partitioned into one of two compartments for fat mass and for fat-free mass:

$$
\frac{d f m(t)}{d t}=\frac{(1-r(t)) e b(t)}{\rho_{f m}}
$$




$$
\frac{d f f m(t)}{d t}=\frac{r(t) e b(t)}{\rho_{f f m}}
$$

where $r(t)$ ratio is the parameter that assigns a percentage of the imbalance denoted by $e b(t)$ to the compartments fat mass and fat-free mass, respectively (Dugdale \& Payne, 1977):

$$
\begin{gathered}
r(t)=\frac{K}{K+f m(t)} ; \quad K=10.4 \frac{\rho_{f f m}}{\rho_{f m}} \\
\rho_{f f m}=1800 \mathrm{kcal} / \mathrm{kg} \\
\rho_{f m}=9400 \mathrm{kcal} / \mathrm{kg}
\end{gathered}
$$

It is important to mention that also more precise (and complex) mathematical models describing the influence of eating and physical activity to body mass exist. But in our case the goal was mainly to present the interdependence of different models and information which can be shared to obtain better insight into population behaviour what is also the reason why in this modelling step only an average person (between men and women) was taken into account. From the average height $(1.72 \mathrm{~m}$ regarding 11 European countries) and average $\mathrm{BMI}=32$ also the average mass of this person is estimated to be $94.7 \mathrm{~kg}$. Regarding medical recommendations such person should loose around $30 \mathrm{~kg}$ to satisfy BMI $=22$ in the middle of desired BMI interval. The initial fat mass was estimated from the regression equations (Jackson et al., 2002): $f m(0)=34.7 \mathrm{~kg}$.

Model response is given in Fig. 17 for observation time of 10 years. During the first year (365 days) energy intake is equal to energy expenditure (2460kcal) (for control purposes) and therefore the body mass remains unchanged. After the first year physical activity is increased from 370kcal per day (representing minimal physical activity) for $210 \mathrm{kcal}$ per day. This energy expenditure can be realized by a half an hour walk, but without the increase of energy intake. Such minimal increase of activity, which is in general suitable also for obese persons, would change in three years BMI to 25.

In our case however, at the beginning of the third year of observation also the energy intake is decreased for $300 \mathrm{kcal}$ per day, but only for one year. In this way desired range of BMI is reached during the second year as presented in Fig. 17. If the person remains active for half an hour per day he-she is reaching desired mass at the end of the third year.

What direct changes could such a regime of activity and diet represent for observed population and why the problems are expected in practice?

Let's take into account the following assumptions. $80 \%$ of obese and inactive people between the age of 20 to 50 are motivated to undertake the presented regime of increased activity and diet. With this they are immediately transferred into the group of active population, where they remain. After two years of activity they are also transferred out from obese population and they remain in the group of people with healthy body mass. Each year also $80 \%$ of 20 years old obese and inactive are motivated to join the motivated group.

The consequences of life - lasting increased activity together with corresponding diet are shown in Figs. 18 to 20. The increased number of active population (Fig. 18) would together with proposed diet slowly changing the number of overweight and obese people (Fig. 19). 


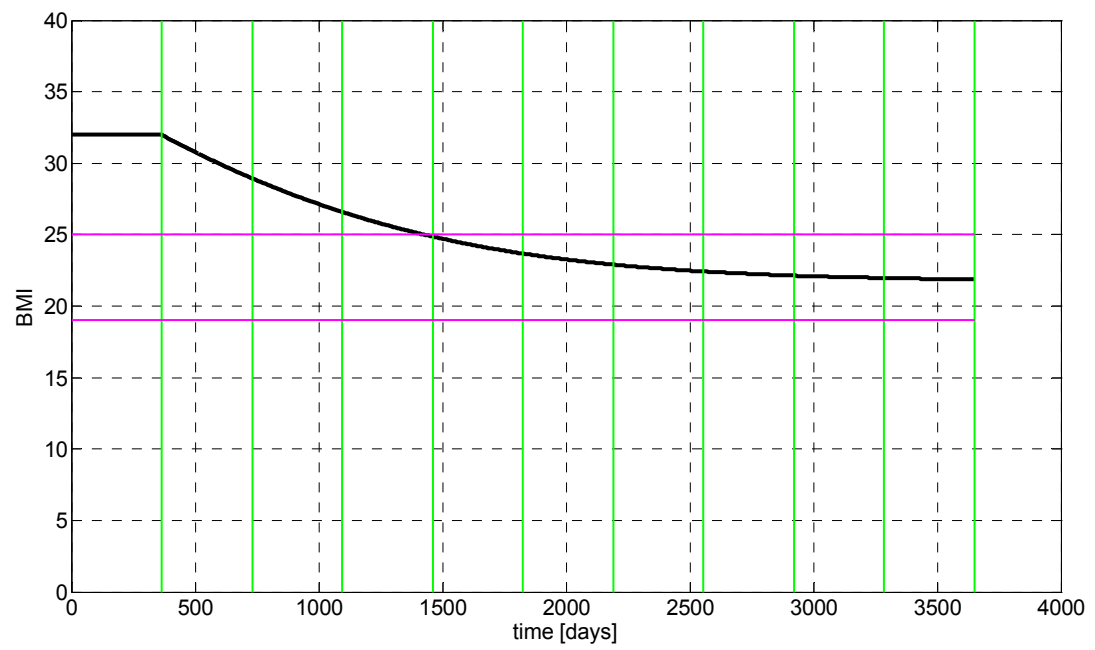

Fig. 17. BMI changing in an average person

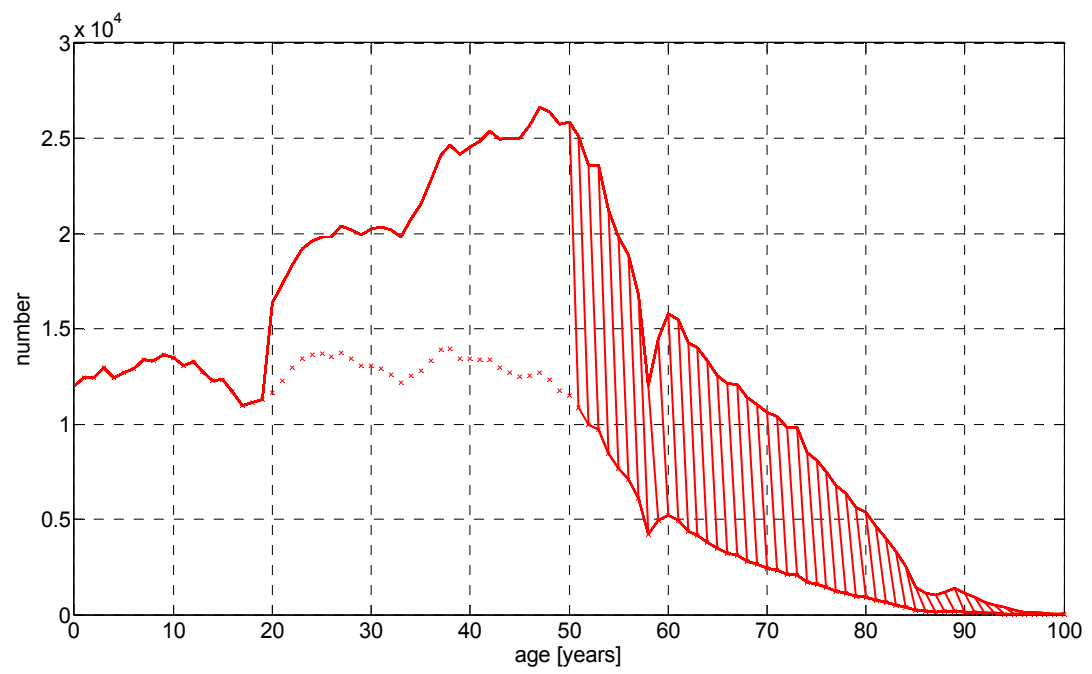

Fig. 18. Activity is increasing 


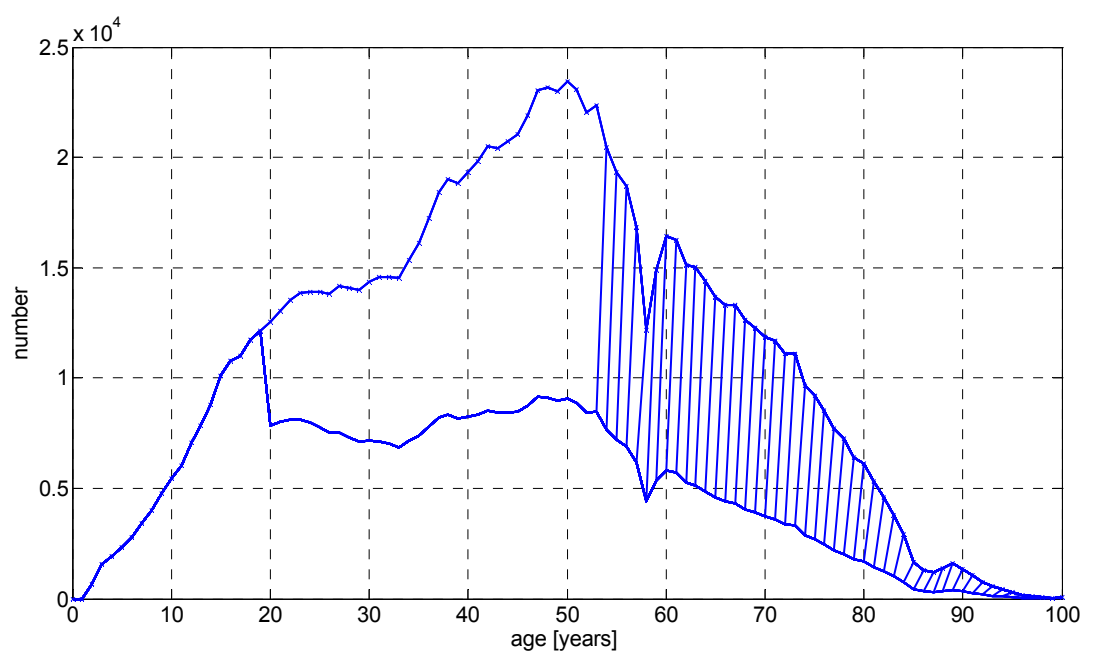

Fig. 19. Number of overweight and obese patients is decreasing

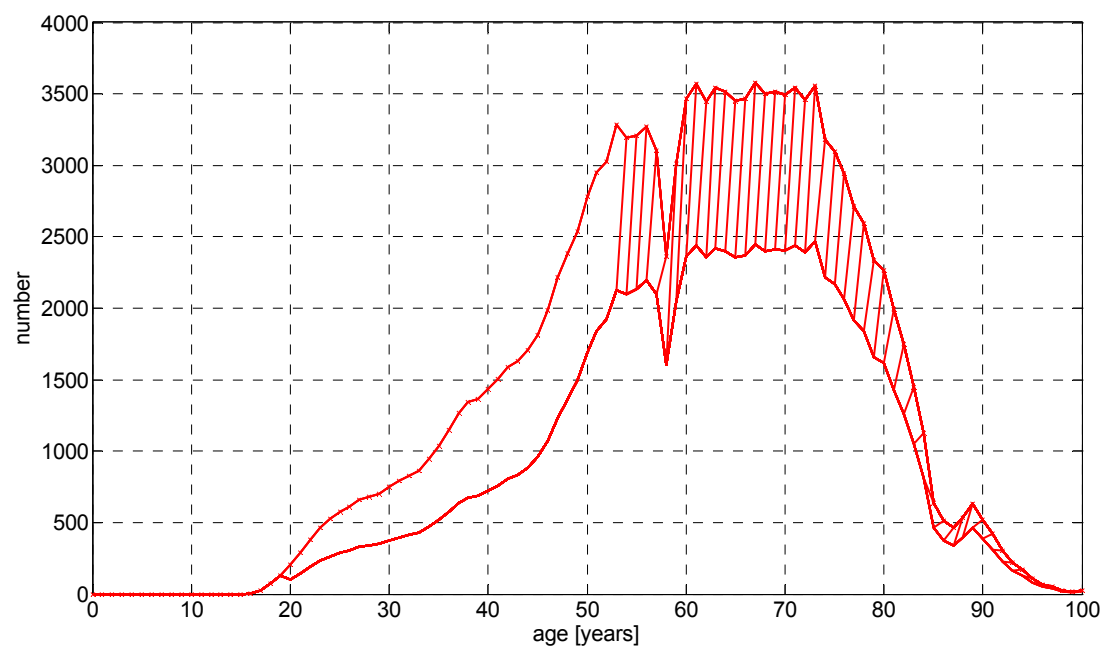

Fig. 20. Number of D2 patients is decreasing 
The consequence would be that among this group of patients from pre-diabetes only $50 \%$ would develop D2, while other would return to the population with healthy body mass and without D2 (Fig 20).

In this way the number of obese and overweight people would be decreased for over $53 \%$ and the number of D2 patients for $35 \%$. In the same proportion also the corresponding expenses would be reduced.

The proposed strategy has one important deficiency, namely the lack of patients' motivation and discipline as the success is completely dependent on these two important factors. Therefore our further goal is to extend the presented model with motivation aspects and expenses needed for its stimulation.

\section{Conclusion}

Four-level mathematical description structure is proposed which can be efficiently used for the estimation of the number of observed patients, the distribution regarding their age and for the estimation of their economical burden. It can comprise different mathematical descriptions important for observed processes. In our case it consists of dynamical decision tree describing the prevalence of population activity and inacivity, overweight and obesity, pre-diabetes and diabetes type 2 . In combination with dynamical population model predicting the number of people, two-compartment dynamical model for estimation of body mass changes and evaluated treatment expenses also the number of observed patients and treatment burden were calculated for Slovenia. As similar results can be expected in the countries with comparable social and economical situation (the great majoity of EU countries), the following can be concluded for the population of one million people:

- over $60 \%$ are inacive,

- only $45 \%$ have body mass in normal range,

- $\quad$ overweight and obese patients spend around $€ 65.5$ million per year for body mass reduction,

- $30 \%$ of people has pre-diabetes,

- $\quad$ over $7 \%$ have developed diabetes type 2 ,

- direct tratment expenses for D2 patients are around $€ 25.5$ million,

- $\quad$ essential savings could be expected with minimal life-style changes,

- in this way the number of obese and overweight people could be decreased for over $53 \%$ and the number of D2 patients for over $35 \%$.

It is obvious that motivation is the most important obstacle in achieving the efficient improvement in reduction of D2 patients and corresponding economical burden. Therefore our future interest will be directed in developing corresponding mathematical model to complement the presented structure and to indicate the potentially important further activities.

\section{Acknowledgment}

The authors sincerely thank prof. dr. Rihard Karba, University of Ljubljana, Faculty of Electrical Engineering, for the fruitful discussions and his suggestions which have significantly influenced the work. 


\section{References}

ADA - American Diabetes Association (2007). Standards of medical care in diabetes - 2007, Diabetes Care, 2007, Jan;30, Suppl 1:S4-S41, ISSN 0149-5992.

Arnold, R. J. G. (Editor) (2010). Pharmacoeconomics, From Theory to Practice, CRC Press, Taylor \& Francis Group, Drug Discovery Series/13, ISBN 978-1-4200-8422, Boca Raton.

Atanasijević-Kunc, M.; Drinovec, J. \& Mrhar, A. (2008a). Usage of Modelling and Simulation in Medicine and Pharmacy. Journal of Slovene Medical Society, Vol. 77, No. 1, (2008), pp. 57-71, ISSN 1318-0347.

Atanasijević-Kunc, M.; Drinovec, J.; Ručigaj, S. \& Mrhar, A. (2008b). Modelling of the risk factors and chronic diseases that influence the development of serious health complications. Journal of Slovene Medical Society, Vol. 77, No. 8, (2008), pp. 487-498, ISSN 1318-0347.

Atanasijević-Kunc, M.; Drinovec, J.; Ručigaj, S. \& Mrhar, A. (2008c). Modeling the influence of risk factors and chronic diseases on the development of strokes and peripheral arterial-vascular disease. Simulation modelling practice and theory, Vol. 16, No. 8, (2008), pp. 998 -1013, ISSN 1569-190X, doi: DOI:10.1016/j.simpat. 2008.03.008.

Atanasijević-Kunc, M.; Drinovec, J.; Ručigaj, S. \& Mrhar, A. (2011). Simulation analysis of coronary heart disease, congestive heart failure and end-stage renal disease economic burden. Mathematics and Computers in simuation, pp. 1-14, ISSN 0378 4754,<http://dx.doi.org/10.1016/j.matcom.2010.10.024>, doi: 10.1016/j.matcom.2010.10.024.

Behl, G. F. E., Copeland, J. A., Wiggins, J. (2004). The District of Columbia Diabetes Surveillance Report, DC Department of Health, Washington, DC, September 2004, <http://dchealth.dc.gov/doh/lib/doh/services/special_programs/diabetes/pdf/ final data_and_stat_diabetes.pdf. \#search $=\% 22$ columbia $\% 20$ diabetes $\% 20$ prevalence $\% 22>$.

Bellazzi R., Nucci G. \& Cobelli C. (2001). The Subcutaneous Route to Insulin Dependent Diabetes Therapy: Closed-Loop and Partially Closed-Loop Control Strategies for insulin Delivery and Measuring Glucose Concentration. IEEE Engineering in Medicine and Biology Magazine, 2001, 20(1), pp.54-64, ISSN: 0739-5175.

Belič, A. (2009). Modelling in systems biology, neurology and pharmacy. Mathematical and Computer Modelling of Dynamical Systems, Vol. 15, No. 6, (2009), pp. 479 - 491, ISSN 1387-3954, <http://dx.doi.org/10.1080/13873950903375304>, doi:10.1080/13873950903375304.

Berghöfer, A., Pischon, T., Reinhold, T., Apovian, C. M., Sharma, A. M. \& Willich, S. N. (2008). Obesity prevalence from a European perspective: a systematic review, BMC Public Health, 2008, 8:200, doi:10.1186/1471-2458-8-200, ISSN 14712458.

Boutayeb, A.; Twizell, E. H.; Achouayb, K. \& Chetouani, A. (2004). A mathematical model for the burden of diabetes and its complications. BioMedical Engineering OnLine, Vol. 3, No. 20, (2004), doi:10.1186/1475-925X-3-20. 
Boutayeb, A. \& Chetouani, A. (2006). A critical review of mathematical models and data used in diabetology, BioMedical Engineering OnLine, Vol. 5, No. 43, (2006), ISSN: 1475-925X, doi:10.1186/1475-925X-5-43.

Boutayeb, A., Chetouani, A., Achouyab, K. \& Twizell, E. H. (2006). A non-linear population model of diabetes mellitus. Journal of Applied Mathematics and computing, Vol. 21, pp. 127-139, ISSN 15985865.

British Heart Foundation Statistics Website (2008). Age differences and physical activity, <http:/ / www.heartstats.org/atozpage.asp?id=4955>.

British Heart Foundation Statistics Website (2010). Trends in the prevalence of overweight and obesity, <http://www.heartstats.org/ datapage.asp?id=1011>.

Briggs, A. \& Sculpher, M. (1998). An Introduction to Markov Modeling for Economic Evaluation. PharmacoEconomics, 13(4), 1998 , pp. 397-409, ISSN 1170-7690.

Brock, D. W., Thomas, O., Cowan, C. D., Allison, D. B., Gaesser, G. A. \& Hunter, G. R. (2009). Association Between Insufficiently Physically Active and the Prevalence of Obesity in the United States, Journal of physical activity $\mathcal{E}$ health, 2009, January, Vol. 6, No. 1, pp.1-5, ISSN 1543-3080.

Cassandras, C.G., Lafortune S. (1999). Introduction to Discrete Evant Systems. Kluwer Academic Publishers, Boston, ISBN 0-7923-8609-4.

Cellier, F. E.(1991). Continuous System Modeling. Springer-Verlag, New York, ISBN 0-38797502-0.

Cellier, F. E. \& Kofman, E. (2006). Continuous System Simulation, Springer Science + Business Media, New York, ISBN 0-387-26102-8.

Chow, C. C. \& Hall, K. D. (2008). The dynamics of human body weight change, PLoS Computational Biology, Vol. 4, No. 3, pp. 1-13, ISSN 1553-734X.

Daousi, C., Casson, I. F., Gill, G. V., MacFarlane, I. A., Wilding, J. P. H.\& Pinkney, J. H. (2006). Prevalence of obesity in type 2 diabetes in secondary care: association with cardiovascular risk factors, Postgraduate Medical Journal, 2006; Vol. 82, pp. 280-284 doi:10.1136/pmj.2005.039032, ISSN 00325473.

Defay, R., Delcourt, C., Ranvier, M., Lacroux, A. \& Papoz, L. (2001). Relationships between physical activity, obesity and diabetes mellitus in a French elderly population: the POLA study, International Journal of Obesity, 2001, Vol. 25, No. 4, pp. 512-518, ISSN 0307-0565.

DPPRG - Diabetes Prevention Program Research Group, (2002). Reduction in the Incidence of Type 2 Diabetes with Lifestyle Intervention or Metformin, The New England Journal of Medicine, 2002, Vol. 346, pp. 393-403, ISSN 1533-4406.

Dugdale, A. \& Payne, P. (1977). Pattern of lean and fat deposition in adults, Nature, Vol. 266, pp. 349-351, ISSN 0028-0836.

Eddy, D. M. \& Schlessinger, L. (2003a). Archimedes, A trial-validated model of diabetes. Diabetes Care, Vol. 26, No. 11, (2003), pp. 3093-3101, Online ISSN 1935-5548

Eddy, D. M. \& Schlessinger, L. (2003b). Validation of the Archimedes Diabetes Model. Diabetes Care, Vol. 26, No. 11, (2003), pp. 3102-3110, Online ISSN 1935-5548.

HER (2001). Human energy requirements, Report of a Joint FAO/WHO/UNU Expert Consultation, Rome, 17-24 October 2001, ISBN 92-5-105212-3, ISSN 1813-3932, <http://www.fao.org/docrep/007/y5686e/y5686e00.htm>. 
Homer, J., Jones, A., Seville, D., Essien, J., Milstein, B. \& Murphy, D. (2004). The CDC's Diabetes Systems Modeling Project: Developing a New Tool for Chronic Disease Prevention and Control. 22nd International Conference of the System Dynamics Society, July 25-29, 2004 (Oxford, England),

<http://www.sustainabilityinstitute.org/pubs/Diabetes_System(ISDC04).pdf>.

Hoppensteadt, F. C. \& Peskin, C. S. (2002). Modeling and Simulation in Medicine and the Life Sciences, Springer-Verlag, New York, ISBN 0-387-95072-9.

D'Inverno, M. \& Luck, M. (2010). Understanding Agent Systems. Springer-Verlag, Berlin, ISBN 978-3-642-07382-3.

Jackson, A. S., Stanforth, P. R., Gagnon, J., Rankinen, T., Leon, A. S., Rao, D. C., Skinner, J. S., Bouchard, C. \& Wilmore, J. H. (2002). The effect of sex, age and race on estimating percentage body fat from body mass index: The heritage family study, International Journal of Obesity, Vol. 26, pp. 789-796, doi:10.1038/sj.ijo.0802006, ISSN 0307-0565.

Kriska, A. M., Saremi, A., Hanson, R. L., Bennett, P. H., Kobes, S., Williams, D. E. \& Knowler, W. C. (2003). Physical Activity, Obesity, and the Incidence of Type 2 Diabetes in a High-Risk Population, American Journal of Epidemiology, 2003, Vol. 158, No. 7, DOI: 10.1093/aje/kwg191, ISSN 0002-9262.

Kristöfel, P., Breitenecker, F., Gyimesi, M. \& Popper, N. (2007). A System Dynamics Model for the Diabetes Prevalence in Austria, Proc. EUROSIM 2007, 9-13 Sept. 2007, Ljubljana, Slovenia, ISBN 978-3-901608-32-2.

Lam, Z. H., Hwang, K.S., Lee, J. Y., Chase, J. G. \& Walker, G. C. (2002). Active insulin infusion using optimal and derivative weighted control. Medical engineering physics, 2002, Vol. 24, pp. 663-672, ISSN 1350-4533.

Levenson, J. W., Skerrett, P. J., Gaziano, J. M. (2002). Reducing the Global Burden of Cardiovascular Disease: The Role of Risk Factors. Preventive Cardiology, Fall 2002, Vol. 5, pp. 188-199, ISSN 1520-037X.

Li C., Ford, E. S., Zhao, G. \& Mokdad, A. H. (2009). Prevalence of Pre-Diabetes and Its Association With Clustering of Cardiometabolic Risk Factors and Hyperinsulinemia Among U.S. Adolescents, Diabetes Care, Vol. 32, No. 2, 2009, pp. 342-347, ISSN: 1935-5548.

Makroglou, A.; Li, J. \& Kuang, Y. (2006). Mathematical models and software tools for the glucose-insulin regulatory system and diabetes: an overview. Applied Numerical Mathematics, Vol. 56, Iss. 3-4, (2006), pp. 559-573, Selected Papers, The Third International Conference on the Numerical Solutions of Volterra and Delay Equations, ISSN 0168-9274.

Matko, D.; Karba, R. \& Zupančič, B. (1992). Simulation and Modelling of Continuous Systems, A Case Study Approach, Prentice Hall, New York, ISBN 0-13-808064-X

Matlab, (2005). Reference Guide, The MathWorks Inc.

MMWR (2004). Prevalence of Overweight and Obesity Among Adults with Diagnosed Diabetes - United States, 1988--1994 and 1999-2002, (2004). Morbidity and Mortality Weekly Report (MMWR), 53(45); pp. 1066-1068, 2004, Centers for Disease Control and Prevention (CDC), ISSN 0149-2195,

<http://www.cdc.gov/mmwr/preview/mmwrhtml/mm5345a2.htm>. 
Mokdad, A. H., Ford, E. S., Bowman, B. A., Dietz, W. H., Vinicor, F., Bales, V. S. \& Marks, J. S. (2003). Prevalence of Obesity, Diabetes, and Obesity-Related Health Risk Factors, 2001, JAMA, The Journal of the American Medical Association, 2003; Vol. 289, No. 1, pp. 76-79, doi: 10.1001/jama.289.1.76, ISSN 00987484.

Narayanappa, D., Rajani, H. S., Mahendrappa, K. B. \& Prabhakar, A. K. (2011). Prevalence of Prediabetes in School-Going Children, Indian Pediatrics, Vol. 48, 2011, pp. 295-299, ISSN 0019-6061.

NDS (2011). National Diabetes Statistics, 2011, U.S. Department of Health and Human Services, National Institutes of Health, NIH Publication No. 11-3892, February 2011,

<http://diabetes.niddk.nih.gov/DM/PUBS/statistics/DM_Statistics.pdf>.

Shianga, K.D. \& Kandeelc, F. (2010). A computational model of the human glucose-insulin regulatory system. Journal of Biomedical Research, Vol. 24, Iss. 5, (2010), pp. 347364, ISSN 1552-4965.

Shih, H.C., Chou, P., Liu, C. M. \& Tung, T. H. (2007). Estimation of progression of multistate chronic disease using the Markov model and prevalence pool concept. BMC Medical Informatics and Decision Making, 2007, 7:34, doi:10.1186/1472-6947-7-34, ISSN 1472-6947.

Simulink (2005). User's Guide, The MathWorks Inc.

SORS (2011). Statistical Office of the Republic of Slovenia, <http://www.stat.si/eng/index.asp>.

Stahl, J. E. (2008). Modelling Methods for Pharmacoeconomics and Health Technology Assessment, An Overview and Guide, Pharmacoeconomics, 2008, Vol. 26, No. 2, pp. 131-148, ISSN 1170-7690.

Tarride, J. E., Hopkins, R., Blackhouse, G., Bowen, J. M., Bischof, M., Von Keyserlingk, C., O'Reilly, D., Xie, F. \& Goeree, R. (2010). A Review of Methods Used in Long-Term Cost-Effectiveness Models of Diabetes Mellitus Treatment, Pharmacoeconomics, 2010, Vol. 28, No. 4, pp. 255-277, ISSN 1170-7690.

Tuomilehto, J., Lindström, J. E. J. G., Valle, T. T., Hämäläinen, H., Ilanne-Parikka, P., Keinänen-Kiukaanniemi, S., Laakso, M., Louheranta, A., Rastas, M., Salminen, V., Uusitupa, M. (2001). Prevention of type 2 diabetes mellitus by changes in lifestyle among subjects with impaired glucose tolerance, The New England Journal of Medicine, 2001, Vol. 344, No. 18, pp. 1343-1350, ISSN 1533-4406.

Valensi, P., Schwarz, P., Hall, M., Felton, A. M., Maldonato, A. \& Mathieu, C. (2005). Prediabetes essential action: a European perspective, Diabetes \& Metabolism, Vol 31, No. 6, 2005, pp. 606-620, ISSN 1262-3636, doi : DM-12-2005-31-6-1262-3636-101019200516342.

WHO - World Health Organization (2000), Technical report series 894: Obesity: Preventing and managing the global epidemic. Geneva: World Health Organization. ISBN 92-4-120894-5, <http://whqlibdoc.who.int/trs/WHO_TRS_894_(part1).pdf>.

WHO - World health organization (2011a). Diabetes Programme, Prevalence data, <http://www.who.int/diabetes/facts/world_figures/en/index.html>. 
WHO - World health organization (2011b), Obesity and overweight, Fact sheet N$^{\circ} 311$, March 2011,

<http://www.who.int/mediacentre/factsheets/fs311/en/>. 


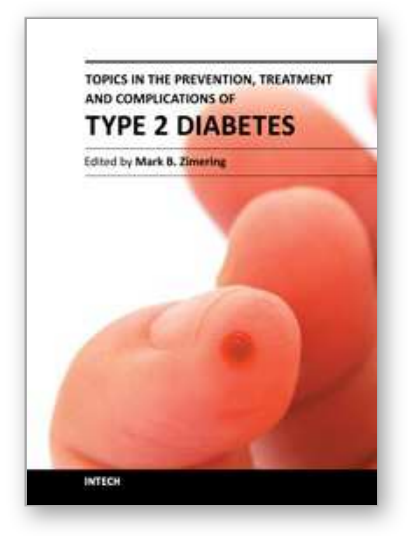

\author{
Topics in the Prevention, Treatment and Complications of Type 2 \\ Diabetes \\ Edited by Prof. Mark Zimering
}

ISBN 978-953-307-590-7

Hard cover, 340 pages

Publisher InTech

Published online 04, November, 2011

Published in print edition November, 2011

Type 2 diabetes is estimated to affect 120 million people worldwide- and according to projections from the World Health Organization this number is expected to double over the next two decades. Novel, cost-effective strategies are needed to reverse the global epidemic of obesity which is driving the increased occurrence of type 2 diabetes and to less the burden of diabetic vascular complications. In the current volume, Topics in the Prevention, Treatment and Complications of Type 2 Diabetes, experts in biology and medicine from four different continents contribute important information and cutting-edge scientific knowledge on a variety of topics relevant to the management and prevention of diabetes and related illnesses.

\title{
How to reference
}

In order to correctly reference this scholarly work, feel free to copy and paste the following:

Maja Atanasijević-Kunc and Jože Drinovec (2011). Burden of Diabetes Type 2 Through Modelling and Simulation, Topics in the Prevention, Treatment and Complications of Type 2 Diabetes, Prof. Mark Zimering (Ed.), ISBN: 978-953-307-590-7, InTech, Available from: http://www.intechopen.com/books/topics-in-theprevention-treatment-and-complications-of-type-2-diabetes/burden-of-diabetes-type-2-through-modelling-andsimulation

\section{INTECH}

open science | open minds

\section{InTech Europe}

University Campus STeP Ri

Slavka Krautzeka 83/A

51000 Rijeka, Croatia

Phone: +385 (51) 770447

Fax: +385 (51) 686166

www.intechopen.com

\section{InTech China}

Unit 405, Office Block, Hotel Equatorial Shanghai

No.65, Yan An Road (West), Shanghai, 200040, China

中国上海市延安西路65号上海国际贵都大饭店办公楼405单元

Phone: +86-21-62489820

Fax: +86-21-62489821 
(C) 2011 The Author(s). Licensee IntechOpen. This is an open access article distributed under the terms of the Creative Commons Attribution 3.0 License, which permits unrestricted use, distribution, and reproduction in any medium, provided the original work is properly cited. 